\section{BEYOND RACE}

Programs in several countries target multiple forms of social inequality and avoid solely race-conscious policies. Brazilian affirmative action is race-conscious but also includes other students considered to be disadvantaged, such as graduates of government secondary schools or students with low-family income. Even South Africa, only free from apartheid for two decades, has some alternate access programs that have begun admitting disadvantaged white students, and other admissions programs consider a range of socioeconomic indicators related to housing, schooling, and family circumstances.

Some policies attempt to combine poverty with other indicators of disadvantage to select students, such as French policies prioritizing and recruiting from low-income neighborhoods or schools, based in ZEPs (Zones d'Education Prioritaire, or priority education areas). An inverse strategy to achieve similar ends excludes the wealthy, as in India's policy of skimming the economic "creamy layer" of more prosperous individuals from eligibility for reserved seats for the groups officially designated as "Other Backward Classes" - a category that already combines both caste- and class-conscious criteria. Israel has successfully integrated ethnicity/nationality and socioeconomic status as targets of affirmative action programs aimed at diversifying selective higher education institutions. Admissions categories focus on the structural challenges students face based on living in disadvantaged neighborhoods and attending low-quality secondary schools.

\section{IMPLICATIONS}

What are the implications of these international policy examples for countering social inequality in higher education? Affirmative action is not a comprehensive solution for poverty or discrimination, but systems of higher education can provide more equitable chances for impoverished or underrepresented students to attend selective colleges and universities. Indices, zones, and other measures are not replacing the role of race, ethnicity, or gender in welldesigned affirmative action programs but are increasingly combined with these categories.

So long as past or present racism, casteism, sexism, or other barriers shape opportunities in a particular society, equity policies can be better designed to reflect and counteract the way multiple forms of disadvantage intersect in the lives of students. Whether motivated by a desire to increase access, expand diversity, or simply recalibrate existing policies in response to court rulings or state referenda, administrators and policymakers should look abroad for ideas. Affirmative action is alive and well-and indeed increasing-around the world.

\section{The Economic and Non-} economic Benefits of Tertiary Education in Low-income Contexts

\author{
Rebecca Schendel, Tristan McCowan, and Moses \\ OKETCH
}

Rebecca Schendel is lecturer in Education a International Development, Tristan McCowan is senior lecturer in Education Q International Development, and Moses Oketch is reader in Education Q International Development at the Institute of Education, University of London. E-mails:r.schendel@ioe.ac.uk; t.mccowan@ioe.ac.uk; m.oketch@ioe. ac.uk. Material for this article comes from: Oketch, McCowan, and Schendel, The Impact of Tertiary Education on Development: A Rigorous Literature Review. Download the full review at: http://r4d.dfid.gov. uk/Output/195887/.

$\mathrm{T}$ There have been debates around the social impact of tertiary education in developing countries for decades. In the late I980s, a series of studies commissioned by the World Bank seemed to indicate that, in developing contexts, investment in tertiary education would yield a much lower social return than that in lower levels of education. In contexts where primary education was scarce and illiteracy was rampant, there was a clear economic argument for prioritizing basic education to fuel economic growth. These economic arguments were also supported by social justice concerns that emphasized the ways in which university admissions processes disadvantaged marginalized groups. In contexts where only a small proportion of the population reaches university, advocates for prioritizing funding for primary education have long argued that public support for higher education is likely to perpetuate socioeconomic divisions within society. Although these concerns were valid in many contexts, the unfortunate result was a reduction in both international aid and domestic funding for tertiary education in many low-income contexts, a decision that triggered a "crisis of quality" across the sector.

However, shifts in the nature of production associated with globalization and the rise of the "knowledge economy," as well as increasing demand as a result of expanding primary and secondary enrollment, have redirected international attention to the importance of tertiary education in development. Development agencies and national governments are now considering renewing their financial commitment to tertiary education; and, as a result, the question of impact has returned to the discourse. In line with these developments, the Institute of Education, University 
of London, was recently commissioned by the UK Department for International Development to complete a rigorous review of the evidence of how tertiary education impacts development in lower-income contexts. Although the findings of the review may not always be surprising for those working in the field of international higher education, a number of important social functions of the university have been highlighted that have not been sufficiently emphasized in debates around public funding for tertiary education in the developing world.

\section{ECONOMIC BENEFITS}

In terms of the economic benefits of tertiary education, the review yielded some significant and, in some ways, unexpected findings. The most robust finding was the clear impact that tertiary education appears to have on the individual earnings of graduates. Although this may appear an obvious point, there has not always been a strong relationship between higher education and higher earnings in low-income contexts. However, the findings of the review suggest that, as increasing numbers of young people access lower levels of education, the earnings of higher education graduates have also increased. The review also yielded important evidence of the impact of higher education on economic growth (typically measured as per capita gross domestic product). Given the mixed evidence in the literature around the respective contribution of different levels of education to economic growth, there is clear link between the proportion of individuals with higher education and growth; and some studies suggest that tertiary education may have a greater impact on growth than lower levels.

\section{Noneconomic Benefits}

In addition to economic benefits, the review also highlighted the substantial noneconomic benefits that tertiary education contributes to society. Although the evidence is limited, what exists clearly demonstrates that tertiary education has a positive effect on individual graduate capabilities in a range of different areas-including political participation, health and nutrition, and women's empowerment. The review also identified a number of studies that demonstrate how tertiary education strengthens institutions-such as civil society organizations, governments, and public services-and positively impacts social norms and attitudes toward concepts such as democracy and environmental protection.

\section{Gaps in the Evidence}

Overall, the review exposed a significant lack of robust empirical evidence of impact in less-resourced contexts. Although there is a lot of literature that discusses impact, much of it is normative. From an initial list of nearly 7,000 titles, only 99 studies were included in the final synthesis. Within the existing literature, the body of evidence relating to the economic benefits of tertiary education is substantially larger than that relating to the noneconomic benefits. More research is clearly needed into the ways in which tertiary education contributes to human development in lowincome contexts beyond measures of economic growth.

There is also a clear gap in the evidence around the ways in which different conditions affect impact. While many studies investigate the way that tertiary institutions and systems function, very few consider how the manner in which institutions function impacts development. For example, there is little evidence of how public versus private provision—or how particular models of curricu-

\section{These economic arguments were also supported by social justice concerns that emphasized the ways in which uni- versity admissions processes disadvan- taged marginalized groups.}

lum or modes of delivery (e.g., distance education versus face-to-face)-influence developmental outcomes. There is also little evidence of the impact of changes in other mediating conditions, such as the nature of the job market or the policy environment. Without evidence of how different conditions affect development outcomes, external agencies and national governments run the risk of supporting interventions and reforms that may not ultimately make a positive contribution. Conditions likely to act as barriers to impact include: insufficient primary and secondary education; low quality of teaching and research; limited academic freedom; and inequality of access and opportunities within the tertiary sector. As these conditions are often the norm in low-income contexts, the lack of impact observed in some of the included studies is likely to be the result of such barriers. A supplementary overview of studies assessing interventions funded by external agencies suggests that the most frequent intervention models do not directly address the principal barriers to impact. This finding carries significant implications for reform efforts across the developing world.

In recent years, widespread interest in revitalizing tertiary institutions in low-income contexts has been expressed. This interest has largely been inspired by the notion that tertiary education can be an "engine of development" and reflects an understanding that circumstances are 
changing in many lower-income contexts. As increasing numbers of young people complete primary and secondary education - and as the youth population surges across the globe-tertiary education is positioned as being crucial for economic development. This review supports such assertions. However, it also highlights the diverse noneconomic benefits that should also be acknowledged and considered in the development of policy.

\section{World Economies and the Distribution of International Branch Campuses}

\section{Li Zhang, Kevin Kinser, and Yunyu ShI}

Li Zhang is a doctoral student in the Department of Educational Administration and Policy Studies and research assistant for the CrossBorder Education Research Team (C-BERT) at the State University of New York at Albany. E-mail: Izhang6@albany.edu. Kevin Kinser is associate professor and chair of the Department of Educational Administration and Policy Studies and co-director of C-BERT at the State University of New York at Albany. E-mail: kkinser@albany.edu. Yunyu (Stephanie) Shi is a visiting scholar in the Department of Educational Administration and Policy Studies and researcher for C-BERT at State University of New York at Albany. E-mail: stephaniesyy@hotmail.com.

The international branch campus has become a sym1 bol of higher education internationalization in recent years. Perhaps because the dominant exporting countries have been the United Kingdom, the United States, and Australia, many people assume that the higher education export flows from developed countries to developing countries, in a West-to-East fashion. However, using data from the Cross-Border Education Research Team (C-BERT) at the University at Albany, State University of New York alongside an economic framework provided by the World Economic Forum, we look at the distribution of international branch campuses around the world. There are distinct patterns between host and home countries and the interests countries have for establishing international branch campuses are connected to economic competitiveness.

\section{World EConomic Forum's Global Competitive Index}

Since its development in 2004, the World Economic Forum's global competitive index has been widely used to measure and compare countries' productivity and economic prosperity. It uses I2 competitive index measures, to cat- egorize countries into three types of economies. The index measures are designed to describe economic competitiveness in a country more accurately than the controversial categories of developing or emerging countries.

The first four pillars-institutions, infrastructure, macroeconomic environment, and health and primary education-create factor-driven economies. Fifty-eight countries belong to this category where they use low wages and natural resources for competitive advantage. A second category of 53 efficiency-driven economies are determined by six different pillars: higher education and training, good-market efficiency, labor-market efficiency, financial market efficiency, technology readiness, and market size. These countries compete through the development of a skilled workforce and increased product quality. Finally, innovation-driven economies rely on the two pillars of business sophistication and innovation, to boost their economic development. Thirty-six countries are innovation-driven economies that have advanced production processes and the capacity to create unique products.

Since higher education competitiveness is one indicator of a country's economic competitiveness, the former usually reflects the latter, but that is not always the case. For instance, Bahrain is listed as an innovation-driven economy, but its higher education competitiveness is ranked 53rd among the I47 countries. Barbados, Estonia, Lithuania, Costa Rica, Poland, Chile, and Latvia are efficiency-driven economies, but their higher education competitiveness is on par with that of innovation-driven economies. In the same vein, Saudi Arabia, Brunei, Sri Lanka, Philippines, Venezuela, and Armenia are factor-driven economies with more competitive higher education than many efficiencydriven economies.

\section{International Branch Campuses}

C-BERT has identified 20I international branch campuses in operation worldwide. Using the World Economic Forum framework, we grouped these campuses into 9 categories based on the classification of the home and host countries, as either factor-, efficiency-, or innovation-driven economies.

There are a total of 12 international branch campuses established by 5 factor-driven economies-including India, Iran, Pakistan, Philippines, and Venezuela. All the factordriven economies establish their branch campuses in innovation-driven economies, rather than factor-driven or efficiency-driven economies. United Arab Emirates (UAE) is the biggest importer, hosting eight of such international branch campuses, while India becomes the biggest factordriven exporting economy, having 9 branch campuses worldwide, mainly in UAE. 